\title{
Nuclear receptor corepressor (NCoR) is a positive prognosticator for cervical cancer
}

\author{
Daniel Beilner ${ }^{1} \cdot$ Christina Kuhn $^{1} \cdot$ Bernd P. Kost $^{1} \cdot$ Theresa Vilsmaier $^{1} \cdot$ Aurelia Vattai ${ }^{1} \cdot$ Till Kaltofen $^{1}$. \\ Sven Mahner ${ }^{1}$ - Elisa Schmoeckel ${ }^{2}$ - Christian Dannecker ${ }^{3}$. Julia Jückstock ${ }^{1}$ - Doris Mayr ${ }^{2}$. Udo Jeschke ${ }^{1,3}$ (iD . \\ Helene Hildegard Heidegger ${ }^{1}$
}

Received: 17 November 2020 / Accepted: 27 March 2021 / Published online: 16 April 2021

(c) The Author(s) 2021

\begin{abstract}
Purpose Enzymes with epigenetic functions play an essential part in development of cancer. However, the significance of epigenetic changes in cervical carcinoma as a prognostic factor has not been fully investigated. Nuclear receptor corepressor $(\mathrm{NCoR})$ presents itself as a potentially important element for epigenetic modification and as a potential prognostic aspect in cervical cancer.

Methods By immunohistochemical staining of 250 tumor samples, the expression strength of NCoR was measured and evaluated by immunoreactive score (IRS) in the nucleus and cytoplasm.

Results A low expression of $\mathrm{NCoR}$ in our patients was a disadvantage in overall survival. Expression of NCoR was negatively correlated with viral oncoprotein E6, acetylated histone H3 acetyl K9 and FIGO status, and positively correlated to p53. Conclusions Our study has identified epigenetic modification of tumor cells thus seems to be of relevance in cervical cancer as well for diagnosis, as a marker or as a potential therapeutic target in patients with advanced cervical carcinoma.
\end{abstract}

Keywords NCoR $\cdot$ Epigenetic $\cdot$ Cervical cancer $\cdot$ Prognosis $\cdot$ Immunohistochemistry

Udo Jeschke

udo.jeschke@med.uni-muenchen.de;

udo.jeschke@uk-augsburg.de

Daniel Beilner

daniel.beilner@med.uni-muenchen.de

Christina Kuhn

christina.kuhn@med.uni-muenchen.de

Bernd P. Kost

bernd.kost@med.uni-muenchen.de

Theresa Vilsmaier

theresa.vilsmaier@med.uni-muenchen.de

Aurelia Vattai

aurelia.vattai@med.uni-muenchen.de

Till Kaltofen

till.kaltofen@med.uni-muenchen.de

Sven Mahner

sven.mahner@med.uni-muenchen.de
Elisa Schmoeckel

elisa.schmoeckel@med.uni-muenchen.de

Christian Dannecker

christian.dannecker@uk-augsburg.de

Helene Hildegard Heidegger

helene.heidegger@med.uni-muenchen.de

1 Department of Obstetrics and Gynaecology, LudwigMaximilians-University of Munich, Maistrasse 11, 80337 Munich, Germany

2 Department of Pathology, LMU Munich, Thalkirchner Street 56, 80337 Munich, Germany

3 Department of Obstetrics and Gynaecology, University Hospital Augsburg, Stenglinstr. 2, 86156 Augsburg, Germany 


\section{Introduction}

Cervical cancer is the fourth most frequent cancer in women worldwide with about 570,000 new cases in 2018, and this represents $7.5 \%$ of all female cancer deaths. In less developed regions, cervical cancer is the second most common cancer in women living in this regions, and is about $84 \%$ of the new cases worldwide [1]. In the developed world screening for cervical cancer including cervical cytology, human papillomavirus (HPV) or both as well as HPV vaccination has strongly reduced the incidence of cervical cancer [2]. The two main types of cervical cancer are squamous cell cervical cancer comprising $80-85 \%$ and adenocarcinoma comprising $15-20 \%[3,4]$.

The persistent infection with high-risk human papillomavirus (HR-HPV) is the leading cause of cervical cancer. Papillomaviruses are double-stranded, circular DNA viruses. More than $150 \mathrm{HPV}$ types are identified, and only some of them can infect the cervix, named HR-HPV [5]. The group of low-risk HPV types including HPV 6 and HPV 11 is associated with benign anogenital warts that infrequently progress to cancer and the group of high-risk HPV types including HPV 16 and HPV 18 is associated with lesions that are high risk for malignant progression and for cervical cancer [6].

The two oncoproteins E6 and E7, which are both involved in the cellular transformation, are encoded by the high-risk HPV types [7]. E6 and E7 interact with the regulatory proteins in cells like p53 and the retinoblastoma gene $(\mathrm{Rb})$. The E6 protein of HPV 16 is able to bind the cellular p53 and the E7 protein is able to bind the retinoblastoma tumor suppressor gene product, so they modulate the tumor suppressors and contribute also to carcinogenesis [6, 8]. Further studies are needed to understand the complex mechanism that are modulated by HPV E6 and E7.

For the gene expression, many transcription factors and cofactors are needed. The cofactors can activate (the coactivators) or repress (the corepressors) gene transcription. One of the first identified are the nuclear receptor corepressor (CoRs), which include NCoR (nuclear receptor corepressor). Deregulated function of NCoR has been found in many types of cancers [9]. NCoR levels, for example, are downregulated in invasive ductal breast carcinomas [10]. The important role of NCoR in cancer development such as prostate cancer [11] or leukaemia [12] has been suggested in recent studies. In addition, we could recently show that the NCoR-related proteins RIP140 and LCoR are independent markers for poor prognosis in cervical cancer [13].

To find out the role of NCoR in cervical cancer, more studies are needed, so the aim of our study was to revise the significance of NCoR as a prognostic factor in cervical cancer.

\section{Materials and methods}

\section{Patients}

Our analysis included 250 paraffin-embedded cervical cancer samples. The 250 patients had undergone surgery at the Department of Obstetrics and Gynaecology of the LudwigMaximilians University of Munich (LMU) between 1993 and 2002 to include only patients without HPV vaccination. The median age of the group was 48.0 with a range from 22 to 83 years. The study included only the two most frequent histological subtypes, squamous cell carcinoma and adenocarcinoma, due to the low number of other cases. For the positive control of the staining, we used a placenta tissue supplied from the Department of Obstetrics and Gynaecology of the LMU. Clinical data for statistical analyses and the follow-up data were provided by the Munich Cancer Registry and recruited from medical records (Table 1).

\section{Immunohistochemistry}

Samples of 250 patients were formalin-fixed and paraffinembedded. $3 \mu \mathrm{m}$ tissue slices were obtained from the paraffin material and prepared on microscope slides. In the first step, the slides were pre-treated with Roticlear for deparaffinization followed by washing in $100 \%$ Ethanol. After blocking the endogenous peroxidase with $3 \%$ methanol $/ \mathrm{H}_{2} \mathrm{O}_{2}$, the samples were treated in a descending alcohol series for rehydration and washed in distilled water. In a pressure cooker, the samples were heat-treated in a sodium-citrate buffer ( $\mathrm{pH}=6.0$ ) for $5 \mathrm{~min}$ by up to $100{ }^{\circ} \mathrm{C}$. Then, the samples were first cleaned in distilled water followed by a washing step in PBS-buffer. Before incubating the samples with the primary antibody Anti-NCoR (rabbit IgG, company: abcam, order number: ab3482) for $16 \mathrm{~h}$ at $4{ }^{\circ} \mathrm{C}$, all slides were treated with a blocking solution to avoid unspecific hydrophobic binding. After the incubation, the slides were washed in PBS-buffer and covered with a post-block solution. After one more washing in PBS-buffer and applying the HRP-polymer (mouse/rabbit, company: Zytomed, order number: POLHRP-100), the substrate staining with DAB (company: Dako, order number: K3468) was performed. Immediately, following the counterstaining by Hemalum, in the final step, the tissue was dehydrated in a rising alcohol series and finally covered. Placenta tissue was used as a positive control. After the staining, the slides were evaluated by the immunoreactive score (IRS) with an optical microscope. For microscope images, a light microscope "Immunohistochemistry Type 307-148.001 512 686" (company: Leitz, Germany) and "IH-Camera 3CCD Colour Video Camera" (company: Fissler) was used. For image acquisition, "Discuss" software (Version 4) was used. Time and space 
Table 1 Clinical and pathological parameters of patients included in this study

\begin{tabular}{|c|c|c|}
\hline Clinical parameter & No./total no. & $\%$ \\
\hline \multicolumn{3}{|l|}{ Age } \\
\hline$\leq 50$ years & $141 / 250$ & 56.4 \\
\hline$>50$ years & $105 / 250$ & 42.0 \\
\hline N/A & $4 / 250$ & 1.6 \\
\hline \multicolumn{3}{|l|}{$\mathrm{pN}$} \\
\hline Negative & $151 / 250$ & 60.4 \\
\hline Positive & $97 / 250$ & 38.8 \\
\hline N/A & $2 / 250$ & 0.8 \\
\hline \multicolumn{3}{|l|}{ pT } \\
\hline $\mathrm{T} 1$ & $111 / 250$ & 44.4 \\
\hline $\mathrm{T} 2$ & $128 / 250$ & 51.2 \\
\hline $\mathrm{T} 3 / 4$ & $9 / 250$ & 3.6 \\
\hline \multicolumn{3}{|l|}{ FIGO } \\
\hline I & $64 / 250$ & 25.6 \\
\hline II & $48 / 250$ & 19.2 \\
\hline III & $37 / 250$ & 14.8 \\
\hline IV & $7 / 250$ & 2.8 \\
\hline N/A & $94 / 250$ & 37.6 \\
\hline \multicolumn{3}{|l|}{ Grading } \\
\hline G1 & $20 / 250$ & 8.0 \\
\hline $\mathrm{G} 2$ & $143 / 250$ & 57.2 \\
\hline G3 & $78 / 250$ & 32.2 \\
\hline N/A & $9 / 250$ & 3.6 \\
\hline \multicolumn{3}{|l|}{ Histological subtype } \\
\hline Squamous carcinoma & $202 / 250$ & 80.8 \\
\hline Adenocarcinoma & $48 / 250$ & 19.2 \\
\hline \multicolumn{3}{|c|}{ Recurrence (within 235 months) } \\
\hline None & $190 / 250$ & 76.0 \\
\hline$\geq 1$ & $58 / 250$ & 23.2 \\
\hline N/A & $2 / 250$ & 0.8 \\
\hline
\end{tabular}

resolution data are $760 \times 574$ pixels, and bit depth is $24 \mathrm{~mm}$. According to the expression, the nucleus and cytoplasm of the cervical cancer cells were rated from 0 (no expression) to 12 (very high expression). IRS was calculated from the intensity of the staining $(0=$ not stained; $1=$ low intensity; $2=$ moderate intensity; $3=$ high intensity) multiplied by the percentage of stained cells $(0=$ not stained; $1=1-10 \%$; $2=11-50 \% ; 3=51-80 \% ; 4 \geq 80 \%)$.

\section{Statistics}

For statistical analysis, we created a database using IBM SPSS Statistics version 25 (Amrok, NY, USA). The cumulative survival time was calculated and visualized in Kaplan-Meier curves to compare survival rates. For all statistical results, $p$ was required to be $<0.05$.

\section{Results}

\section{NCoR staining in cervical cancer}

The median cytoplasmic IRS of the staining was 12 compared to a nuclear median IRS of $8.1 .7 \%$ of the patients had no expression in the cytoplasm and $0.4 \%$ no detectable staining in the nucleus. $10.3 \%$ showed a low expression (IRS $=1-5$ ), while $89.7 \%$ presented a high expression (IRS 6-12) in the cytoplasm. In comparison with the nucleus with $17.8 \%$ with a low and $82.2 \%$ with a high expression, the median nuclear IRS for squamous carcinoma was 8 and adenocarcinoma was 8.5. For both histological subtypes, the median cytoplasmic IRS was 12 (Fig. 1). The median IRS in the cytoplasm for grading from $\mathrm{G} 1$ to $\mathrm{G} 3$ was 12 , and the median nuclear IRS was 8 for each grading. Patients with lymph node metastasis $(\mathrm{N}+)$ and without lymph-node metastasis (N-) had a median IRS of 12 in the cytoplasm and a nuclear IRS of 8 for $\mathrm{N}+$ and $\mathrm{N}-$. For FIGO I-III, the median IRS was 12, while FIGO IV showed a median IRS of 8 in the cytoplasm (Fig. 2). In comparison, the nucleus was stained with a median IRS of 8 for FIGO I-III and the median IRS of 3 for FIGO IV. Tumour size showed in the cytoplasm a median IRS of 12 for T1 and T2, while the median IRS of T3/4 was 8 . The nucleus showed a median IRS of 8 for T-status T1 and T2 compared to a median IRS of 6 for tumor size T3/4. Table 2 shows staining results for NCoR in summary.

\section{Correlation analyses of NCoR staining with other parameters in cervical cancer}

We found statistically significant negative correlations of NCoR with E6 ( $p=0.003)$, NCoR with FIGO status $(p=0.004)$, and NCoR with acetylated histone H3 acetyl K9 $(p=0.003)$. A positive correlation was found between NCoR and tumor suppressor p53 ( $p=0.01)$. The results of the correlational analysis are presented in Table 3.

\section{NCoR expression in cervical cancer regarding survival}

Finally, further investigations of prognosis revealed a significant disadvantage of patients with a low nuclear expression of NCoR (IRS $<4)$ in overall survival $(p=0.003)$. As presented in the Kaplan-Meier curve, patients in our study group with a low expression of NCoR were correlated with poor prognosis in overall survival (Fig. 3).

\section{Cox regression}

For further analysis of our collected data, we performed a multivariate cox-regression to detect independent 

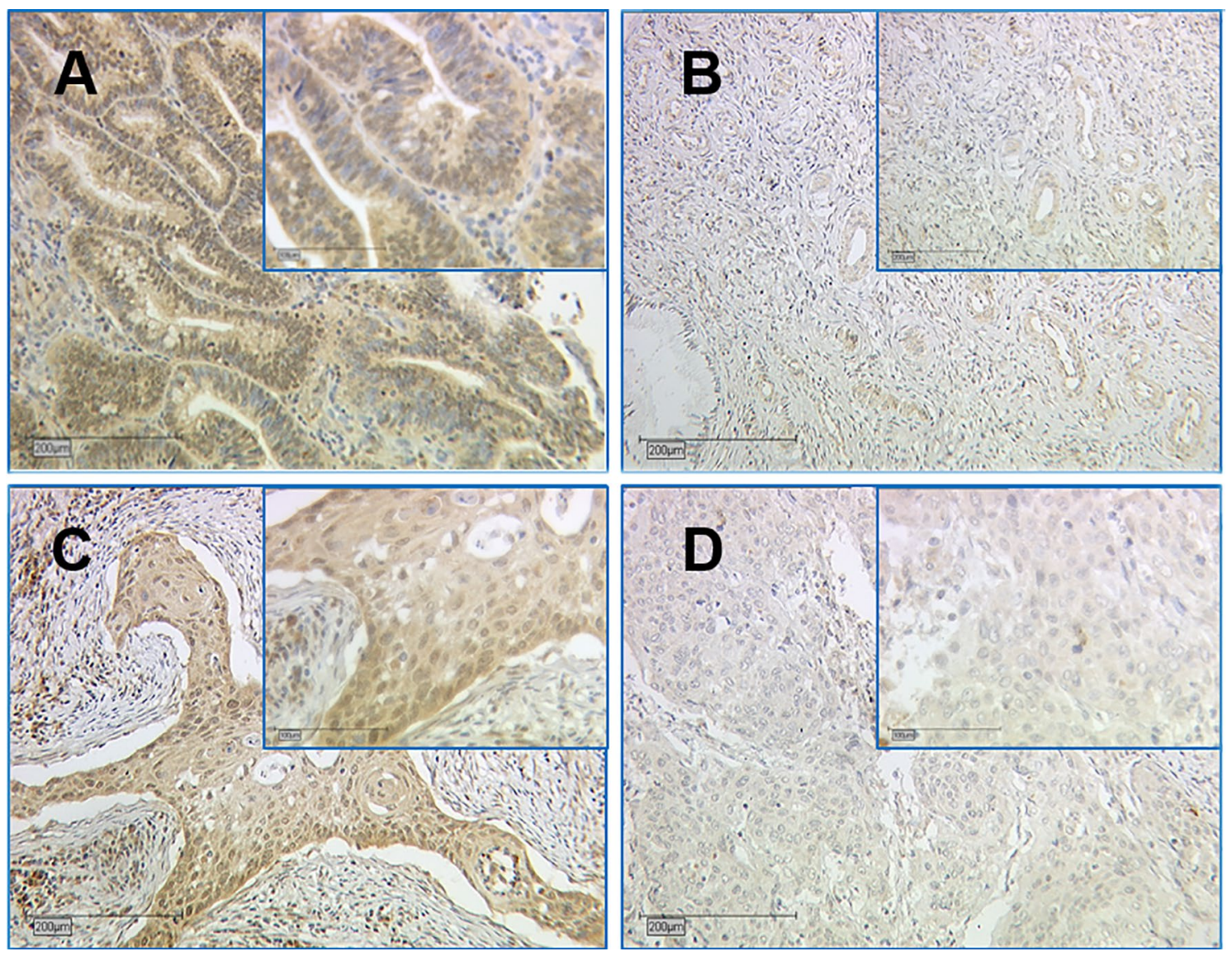

Fig. 1 NCoR staining in cervical cancer. Cytoplasm was scored for image 1a with IRS of 12 (high intensity, $\geq 80 \%$ stained cells), image $1 \mathrm{~b}$ with IRS of 2 (low intensity, 11-50\% stained cells), image 1c with IRS of 12 (high intensity, $\geq 80 \%$ stained cells) and image 1d with IRS of 4 (low intensity, $\geq 80 \%$ stained cells). Nucleus was rated for image a with IRS of 12 (high intensity, $\geq 80 \%$ stained cells), image b with

IRS of 1 (low intensity, 1-10\% stained cells), image $\mathbf{c}$ with IRS of 12 (high intensity, $\geq 80 \%$ stained cells) and image 1d with IRS of 3 (low intensity, $51-80 \%$ stained cells). Image $\mathbf{a} / \mathbf{b}$ were histologically diagnosed as adenocarcinoma compared to image $\mathbf{c} / \mathbf{d}$ as squamosa cell carcinoma. $10 \times$ magnification was used for overview images $(200 \mu \mathrm{m}$ scale bar) with additional $25 \times$ magnification $(100 \mu \mathrm{m}$ scale bar)

Fig. 2 Boxplot summary for FIGO. a Boxplots for cytoplasmic IRS of NCoR and FIGO with a median IRS of 12 for FIGO I-III and a median IRS of 8 for FIGO IV. The asterisk indicates significant lower expression of NCoR in patients with advanced FIGO classification

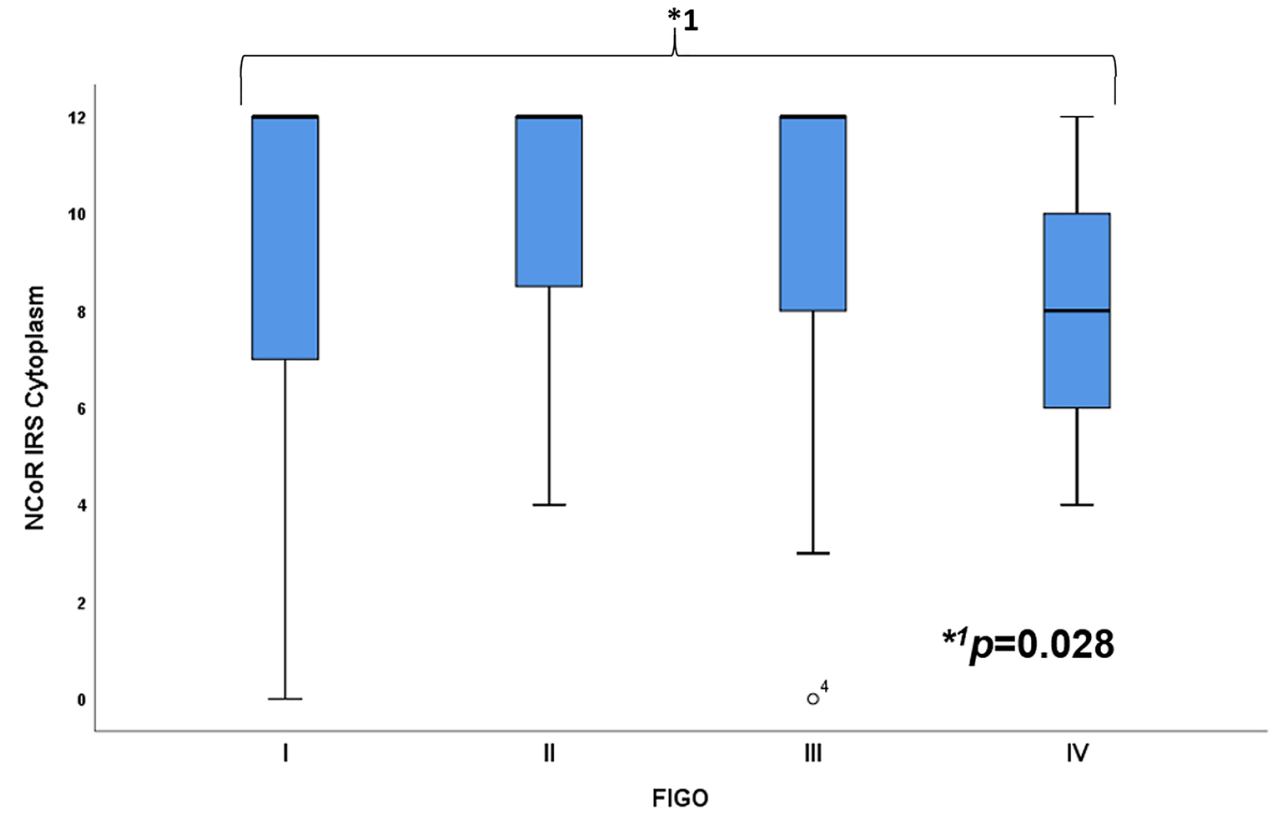


Table 2 Median IRS of NCoR for low and high expression, histological subtype, grading, T-status, $\mathrm{N}$-status and FIGO classification

\begin{tabular}{|c|c|c|}
\hline $\mathrm{NCoR}$ & Cytoplasm & Nucleus \\
\hline Median IRS & 12 & 8 \\
\hline \multicolumn{3}{|l|}{ Expression } \\
\hline No expression & $1.7 \%$ & $0.4 \%$ \\
\hline IRS $1-5$ & $10.3 \%$ & $17.8 \%$ \\
\hline IRS 6-12 & $89.7 \%$ & $82.2 \%$ \\
\hline \multicolumn{3}{|c|}{ Histological subtype (IRS) } \\
\hline Squamous carcinoma & 12 & 8 \\
\hline Adenocarcinoma & 12 & 8.5 \\
\hline \multicolumn{3}{|l|}{ Grading } \\
\hline G1 & 12 & 8 \\
\hline $\mathrm{G} 2$ & 12 & 8 \\
\hline G3 & 12 & 8 \\
\hline \multicolumn{3}{|l|}{ T-status } \\
\hline $\mathrm{T} 1$ & 12 & 8 \\
\hline $\mathrm{T} 2$ & 12 & 8 \\
\hline $\mathrm{T} 3 / 4$ & 8 & 6 \\
\hline \multicolumn{3}{|l|}{$\mathrm{N}$-status } \\
\hline $\mathrm{N}(+)$ & 12 & 8 \\
\hline $\mathrm{N}(-)$ & 12 & 8 \\
\hline \multicolumn{3}{|l|}{ FIGO } \\
\hline I & 12 & 8 \\
\hline II & 12 & 8 \\
\hline III & 12 & 8 \\
\hline IV & 8 & 3 \\
\hline
\end{tabular}

Table 3 Correlation analyses of NCoR staining with other parameters in cervical cancer

\begin{tabular}{lrrrl}
\hline & E6 & FIGO & H3 acetyl K9 & p53 \\
\hline Correlation & -0.193 & -0.184 & -0.193 & 0.166 \\
$p$ & 0.003 & 0.004 & 0.003 & 0.01 \\
\hline
\end{tabular}

There are statistically significant negative correlations of NCoR with E6 $(p=0.003)$, with FIGO status $(p=0.004)$ and with acetylated histone H3 acetyl K9 $(p=0.003)$. A positive correlation was found between NCoR and tumour suppressor p53 $(p=0.01)$

histological parameters for survival in our study group. For overall survival, the histological subtype $(p=0.007)$, pTstatus $(p=0.016)$, and nuclear NCoR expression were independent prognosticators (Table 4).

\section{Discussion}

Our results provide further evidence that epigenetic modulations might play a role in cervical cancer. In this study, we observed that a lower nuclear expression of NCoR was related to a significant disadvantage in overall survival. In further analysis of this patient collective, we identified a negative correlation of NCoR to HPV E6 oncoprotein [14, 15]. Our results suggest that connections of NCoR and E6 oncoprotein for patients diagnosed with cervical cancer which might be of relevance for better survival.

Disruption of epigenomic control can be classified as an enabling characteristic of cancer cells and essential for mutation and malignancy [16-18]. Epigenetic modifications have a strong influence on the expression of the DNA by regulating the biochemical and structural properties of chromatin [19]. One described mechanism in the complex field of gen regulation is the acetylation of histones by enzymes [20-22]. Increased acetylation of histone lysine residues is associated with increased chromatin accessibility and gene expression [23]. This process of histone acetylation and deacetylation has a major role in modulating chromatin accessibility during transcription, replication, and repair [17, 24, 25]. NCoR is a well-studied regulator of gene expression that assembles a multi-protein complex and binds histone deacetylase HDAC3 [26]. Our results support the idea of the NCoR/ HCD3 complex with crucial deacetylase functions presented through a negative correlation of NCoR with Histone $\mathrm{H} 3$ acetyl $\mathrm{K} 9$ from the previous investigations on this specimen [27]. This study is supporting the idea from the previous observations of NCoR and associated histone deacetylases to be recruited to target genes by interaction with nuclear receptors and other transcription factors, causing chromatin compaction and blocking transcription [28-31]. It is proposed that disruption of cell cycle functions of NCoR has dramatic consequences for the regulation of chromatin structure and genomic stability [26]. Our study provides additional support for crucial cell cycle functions of NCoR also in cervical cancer cells.

Further analysis of our patient's collective presented a negative correlation between the expression of NCoR and HPV E6 oncoprotein [14, 15]. This suggests that a link may exist between both proteins. Prior studies have noted the importance of E6 and E7 in proliferating cells as a trigger factor for HPV-induced malignant transformation [32]. It was shown that the expression of HPV-16 E6 disturbs the genomic structure and induces numerical and structural chromosome instability [33] through proteolytic degradation of p53 [34] or direct DNA modification such as viral DNA integration or methylation of viral promoter regions [35]. It is not surprising that high-risk HPV E6 has been reported to interact with a variety of epigenetic enzymes including DNA methylases and histone-modifying enzymes [36]. Our findings are in accord with recent studies indicating that E6 oncoprotein leads to proteolytic degradation of $\mathrm{p} 53$ provided by a negative correlation of NCoR with E6 and a positive correlation of NCoR with p53.

The negative correlation of NCoR and HPV E6 oncoprotein further supports the idea of E6 and E7 to inhibit 
Fig. 3 Kaplan-Meier analyses for relapse-free survival. High nuclear NCoR expression (IRS $>4$; red) compared to low nuclear expression (IRS $\leq 4$; blue) regarding relapse-free survival $(p=0.003)$

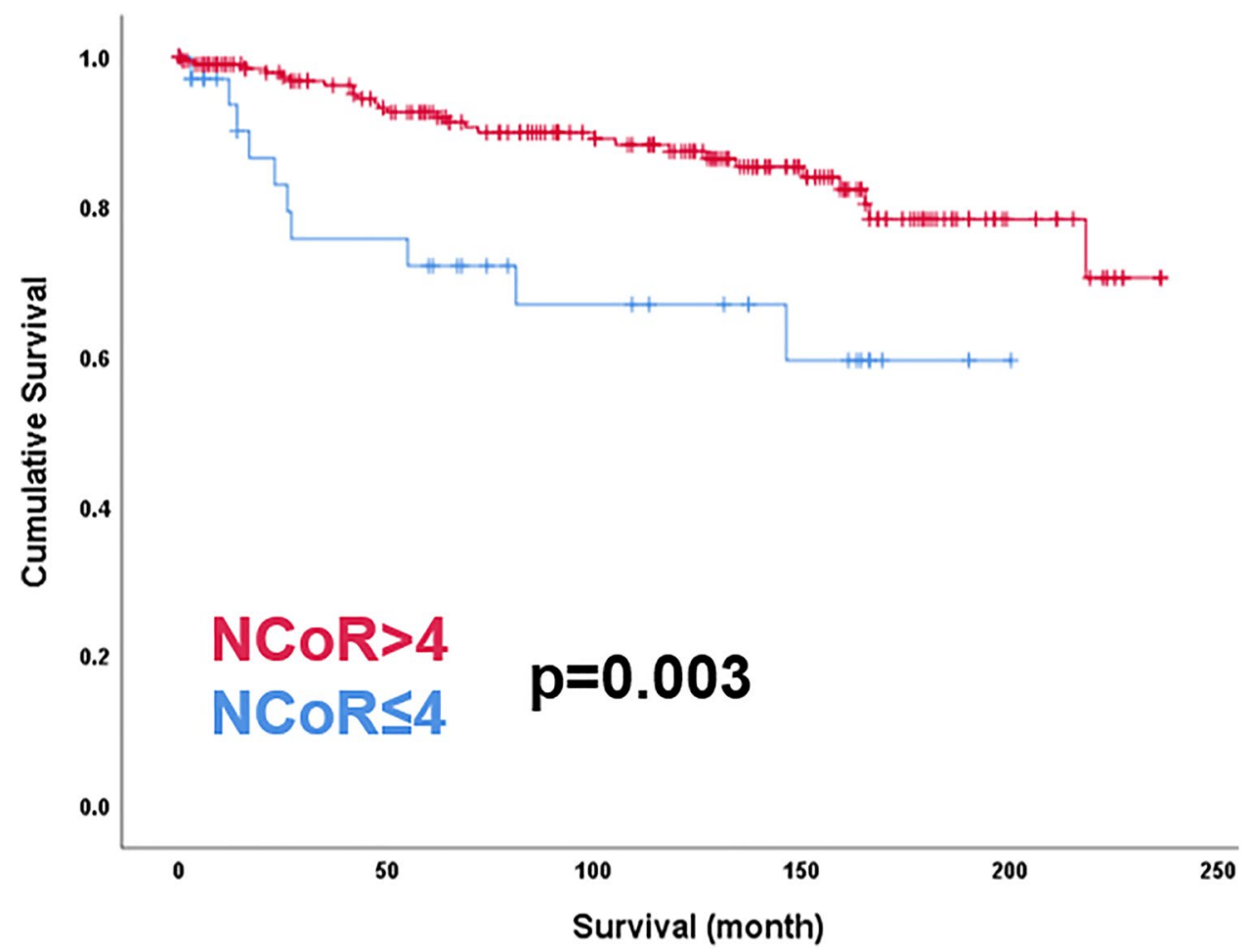

Table 4 Cox regression of clinic pathological variables regarding progress-free survival, histological subtype $(p=0.007)$, pT-status $(p=0.016)$ and nuclear NCoR expression were independent prognosticators

\begin{tabular}{lllll}
\hline Variable & $\begin{array}{l}\text { Signifi- } \\
\text { cance }\end{array}$ & $\begin{array}{l}\text { Hazard } \\
\text { ratio of Exp } \\
\text { (B) }\end{array}$ & $\begin{array}{l}\text { Lower 95\% } \\
\text { CI of Exp } \\
\text { (B) }\end{array}$ & $\begin{array}{l}\text { Upper 95\% } \\
\text { CI of Exp (B) }\end{array}$ \\
\hline Histology & 0.007 & 3.618 & 1.413 & 9.266 \\
pT & 0.016 & 3.311 & 1.252 & 8.753 \\
pN & 0.858 & 0.990 & 0.883 & 1.109 \\
FIGO & 0.718 & 0.880 & 0.439 & 1.763 \\
Grading & 0.369 & 1.435 & 0.652 & 3.155 \\
$\begin{array}{l}\text { NCoR } \\
\text { nucleus } \\
\text { (IRS }>4)\end{array}$ & 0.010 & 0.279 & 0.106 & 0.735 \\
\hline
\end{tabular}

the binding of the histone-deacetylase-3/NCoR complex to the COX-2 promoter [37]. Several reports have shown that prostaglandin derived from COX-2 can stimulate cell proliferation and angiogenesis while inhibiting apoptosis [38-41]. These results provide further support for the hypothesis that HPV oncoproteins can modulate the function of NCoR.

These findings raise intriguing questions regarding the function of NCoR as a gene silencer to replication and transcription in cervical cancer as a defense mechanism. A further study with more focus on the functional significance of $\mathrm{NCoR}$ in cervical cancer cells is, therefore, suggested. This is an important issue for future research to develop a full picture of NCoR as a highly interesting target in diagnostic and pharmaceutical treatment.

The present research aimed to examine the significance of $\mathrm{NCoR}$ as a prognostic factor in cervical cancer. The results present a low expression of NCoR with a significant disadvantage in overall survival. Taken together, this study strengthens the idea that the role of epigenetic modifications through enzymes plays also a crucial role in cervical cancer and provides a deeper insight into the influence of HPV E6 oncoprotein in cervical cancer. A greater focus on $\mathrm{NCoR}$ could produce interesting findings for better diagnostics and therapy in cervical cancer patients.

Authors' contributions All authors analyzed and interpreted the data and read and approved the manuscript. In particular, project development and data collection: $\mathrm{HHH}, \mathrm{BPK}$ and $\mathrm{UJ}$; experiments and methodology: CK and DB; manuscript writing: DB and $\mathrm{HHH}$; supervision: $\mathrm{SM}, \mathrm{CD}, \mathrm{DM}, \mathrm{JJ}, \mathrm{ES}$ and UJ.

Funding Open Access funding enabled and organized by Projekt DEAL. This study was founded by the medical faculty of the LudwigMaximilans-University of Munich.

\section{Declarations}

Conflict of interest SM reports grants and personal fees from AstraZeneca, personal fees from Clovis, grants and personal fees from Medac, grants and personal fees from MSD. He also reports personal fees from Novartis, grants and personal fees from PharmaMar, grants and personal fees from Roche, personal fees from Sensor Kinesis, grants 
and personal fees from Tesaro, grants and personal fees from Teva, outside the submitted study. Christian Dannecker reports personal fees from MSD, Roche, Sanofi and Tesaro outside the submitted study. All the other authors declare no conflict of interest.

Ethical approval and consent to practice The specimens were collected for histopathological diagnostics and used for the study after no clinical use was indicated any longer. The patient data were anonymized and blinded for the authors about clinical information at any time during the experimental analysis. The local committee of the LudwigMaximilians-University of Munich has approved the study (reference number 259-16, 13 June 2016) and was principled conforming to the Declaration of Helsinki.

\section{Consent for publication Not applicable.}

Availability of data and materials The data sets used during the current study are available from the corresponding author on reasonable request.

Code availability Not applicable.

Open Access This article is licensed under a Creative Commons Attribution 4.0 International License, which permits use, sharing, adaptation, distribution and reproduction in any medium or format, as long as you give appropriate credit to the original author(s) and the source, provide a link to the Creative Commons licence, and indicate if changes were made. The images or other third party material in this article are included in the article's Creative Commons licence, unless indicated otherwise in a credit line to the material. If material is not included in the article's Creative Commons licence and your intended use is not permitted by statutory regulation or exceeds the permitted use, you will need to obtain permission directly from the copyright holder. To view a copy of this licence, visit http://creativecommons.org/licenses/by/4.0/.

\section{References}

1. WHO. Human papillomavirus (HPV) and cervical cancer. https:// www.who.int/news-room/fact-sheets/detail/human-papillomav irus-\%28hpv\%29-and-cervical-cancer. Accessed Dec 2019

2. Wentzensen N, Schiffman M (2014) Filling a gap in cervical cancer screening programmes. Lancet Oncol 15:249-251

3. Young RH, Clement PB (2002) Endocervical adenocarcinoma and its variants: their morphology and differential diagnosis. Histopathology 41:185-207

4. Ahn K, Kweon S, Kim DW, Lee H (2019) Different expression of GSK3beta and pS9GSK3beta depending on phenotype of cervical cancer: possible association of GSK3beta with squamous cell carcinoma and pS9GSK3beta with adenocarcinoma. Obstetr Gynecol Sci 62:157-165

5. Schiffman M, Wentzensen N, Wacholder S, Kinney W, Gage JC, Castle PE (2011) Human papillomavirus testing in the prevention of cervical cancer. J Natl Cancer Inst 103:368-383

6. Werness BA, Levine AJ, Howley PM (1990) Association of human papillomavirus types 16 and 18 E6 proteins with p53. Science (New York, NY) 248:76-79

7. Munger K, Phelps WC, Bubb V, Howley PM, Schlegel R (1989) The E6 and E7 genes of the human papillomavirus type 16 together are necessary and sufficient for transformation of primary human keratinocytes. J Virol 63:4417-4421

8. Dyson N, Howley PM, Munger K, Harlow E (1989) The human papilloma virus-16 E7 oncoprotein is able to bind to the retinoblastoma gene product. Science (New York, NY) 243:934-937

9. Wong MM, Guo C, Zhang J (2014) Nuclear receptor corepressor complexes in cancer: mechanism, function and regulation. Am J Clin Exp Urol 2:169-187

10. Kurebayashi J, Otsuki T, Kunisue H, Tanaka K, Yamamoto S, Sonoo H (2000) Expression levels of estrogen receptor-alpha, estrogen receptor-beta, coactivators, and corepressors in breast cancer. Clin Cancer Res Off J Am Assoc Cancer Res 6:512-518

11. Godoy AS, Sotomayor PC, Villagran M, Yacoub R, Montecinos VP, McNerney EM et al (2012) Altered corepressor SMRT expression and recruitment to target genes as a mechanism that change the response to androgens in prostate cancer progression. Biochem Biophys Res Commun 423:564-570

12. Hong SH, David G, Wong CW, Dejean A, Privalsky ML (1997) SMRT corepressor interacts with PLZF and with the PMLretinoic acid receptor alpha (RARalpha) and PLZF-RARalpha oncoproteins associated with acute promyelocytic leukemia. Proc Natl Acad Sci USA 94:9028-9033

13. Vattai A, Cavailles V, Sixou S, Beyer S, Kuhn C, Peryanova M et al (2017) Investigation of RIP140 and LCoR as independent markers for poor prognosis in cervical cancer. Oncotarget 8:105356-105371

14. Stiasny A, Kuhn C, Mayr D, Alexiou C, Janko C, Wiest I et al (2016) Immunohistochemical evaluation of E6/E7 HPV oncoproteins staining in cervical cancer. Anticancer Res 36:3195-3198

15. Stiasny A, Freier CP, Kuhn C, Schulze S, Mayr D, Alexiou C et al (2017) The involvement of E6, p53, p16, MDM2 and Gal-3 in the clinical outcome of patients with cervical cancer. Oncol Lett 14:4467-4476

16. Gronbaek K, Hother C, Jones PA (2007) Epigenetic changes in cancer. APMIS Acta Patholog Microbiolog Immunolog Scand 115:1039-1059

17. Shen H, Laird PW (2013) Interplay between the cancer genome and epigenome. Cell 153:38-55

18. Ting AH, McGarvey KM, Baylin SB (2006) The cancer epigenome-components and functional correlates. Genes Dev 20:3215-3231

19. Schoch H, Abel T (2014) Transcriptional co-repressors and memory storage. Neuropharmacology 80:53-60

20. Kuo MH, Allis CD (1998) Roles of histone acetyltransferases and deacetylases in gene regulation. BioEssays News Rev Mol Cell Dev Biol 20:615-626

21. Chaudary N, Pintilie M, Hedley D, Hill RP, Milosevic M, Mackay $\mathrm{H}$ (2016) Hedgehog inhibition enhances efficacy of radiation and cisplatin in orthotopic cervical cancer xenografts. Br J Cancer 116:50-57

22. Ropero S, Esteller M (2007) The role of histone deacetylases (HDACs) in human cancer. Mol Oncol 1:19-25

23. Fischer A, Sananbenesi F, Wang X, Dobbin M, Tsai LH (2007) Recovery of learning and memory is associated with chromatin remodelling. Nature 447:178-182

24. Gallinari P, Di Marco S, Jones P, Pallaoro M, Steinkuhler C (2007) HDACs, histone deacetylation and gene transcription: from molecular biology to cancer therapeutics. Cell Res 17:195-211

25. Goodarzi AA, Noon AT, Jeggo PA (2009) The impact of heterochromatin on DSB repair. Biochem Soc Trans 37:569-576

26. Bhaskara S, Knutson SK, Jiang G, Chandrasekharan MB, Wilson AJ, Zheng S et al (2010) Hdac3 is essential for the maintenance of chromatin structure and genome stability. Cancer Cell 18:436-447

27. Beyer S, Zhu J, Mayr D, Kuhn C, Schulze S, Hofmann S et al (2017) Histone H3 acetyl K9 and histone H3 tri methyl K4 as prognostic markers for patients with cervical cancer. Int J Mol Sci 18:477 
28. Huang EY, Zhang J, Miska EA, Guenther MG, Kouzarides T, Lazar MA (2000) Nuclear receptor corepressors partner with class II histone deacetylases in a Sin3-independent repression pathway. Genes Dev 14:45-54

29. Perissi V, Jepsen K, Glass CK, Rosenfeld MG (2010) Deconstructing repression: evolving models of co-repressor action. Nat Rev Genet 11:109-123

30. Privalsky ML, Goodson ML (2019) Evolution of NCoR-1 and NCoR-2 corepressor alternative mRNA splicing in placental mammals. BMC Res Notes 12:343

31. Yoon HG, Chan DW, Huang ZQ, Li J, Fondell JD, Qin J et al (2003) Purification and functional characterization of the human N-CoR complex: the roles of HDAC3, TBL1 and TBLR1. EMBO J 22:1336-1346

32. Steenbergen RD, Snijders PJ, Heideman DA, Meijer CJ (2014) Clinical implications of (epi)genetic changes in HPV-induced cervical precancerous lesions. Nat Rev Cancer 14:395-405

33. Duensing S, Munger K (2002) The human papillomavirus type 16 E6 and E7 oncoproteins independently induce numerical and structural chromosome instability. Can Res 62:7075-7082

34. Scheffner M, Huibregtse JM, Vierstra RD, Howley PM (1993) The HPV-16 E6 and E6-AP complex functions as a ubiquitin-protein ligase in the ubiquitination of $\mathrm{p} 53$. Cell 75:495-505

35. Bhattacharjee B, Sengupta S (2006) CpG methylation of HPV 16 LCR at E2 binding site proximal to P97 is associated with cervical cancer in presence of intact E2. Virology 354:280-285
36. McLaughlin-Drubin ME, Munger K (2013) Biochemical and functional interactions of human papillomavirus proteins with polycomb group proteins. Viruses 5:1231-1249

37. Subbaramaiah K, Dannenberg AJ (2007) Cyclooxygenase-2 transcription is regulated by human papillomavirus 16 E6 and E7 oncoproteins: evidence of a corepressor/coactivator exchange. Can Res 67:3976-3985

38. Sheng H, Shao J, Morrow JD, Beauchamp RD, DuBois RN (1998) Modulation of apoptosis and Bcl-2 expression by prostaglandin E2 in human colon cancer cells. Can Res 58:362-366

39. Sheng H, Shao J, Washington MK, DuBois RN (2001) Prostaglandin E2 increases growth and motility of colorectal carcinoma cells. J Biol Chem 276:18075-18081

40. Subbaramaiah K, Dannenberg AJ (2003) Cyclooxygenase 2: a molecular target for cancer prevention and treatment. Trends Pharmacol Sci 24:96-102

41. Tsujii M, Kawano S, Tsuji S, Sawaoka H, Hori M, DuBois RN (1998) Cyclooxygenase regulates angiogenesis induced by colon cancer cells. Cell 93:705-716

Publisher's Note Springer Nature remains neutral with regard to jurisdictional claims in published maps and institutional affiliations. 